\title{
GEDRGES BRLANDIER
}

1920-2016

Por Daniel de Oliveira Cunha

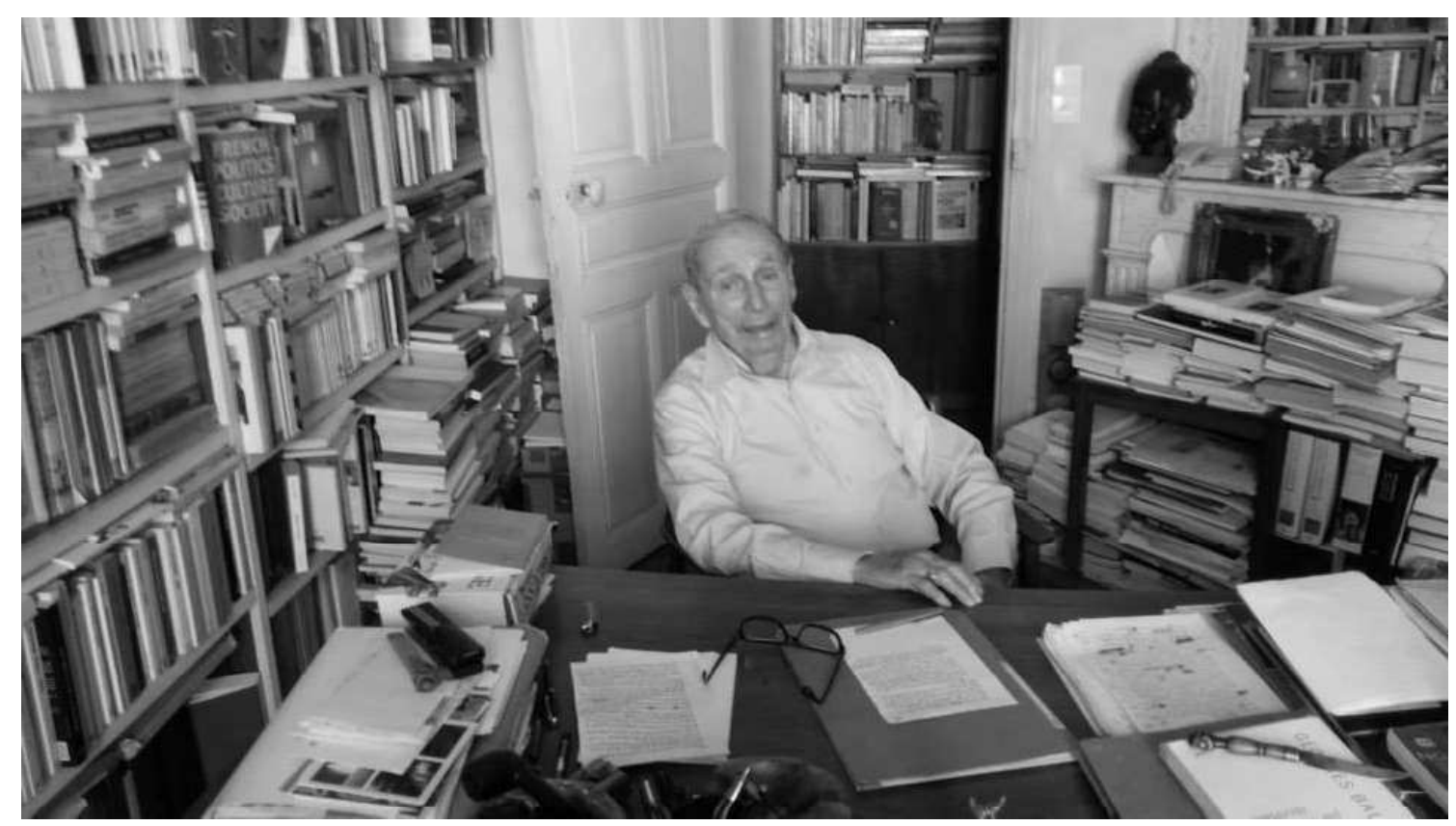

Balandier em sua residência em Paris, 2014.

Foto: Zeila Demartini

Georges Balandier, nascido em 21 de dezembro de 1920, faleceu lúcido e ainda em atividade, pouco antes de completar a idade de 96 anos, no último dia 5 de outubro, em Paris. Natural da comuna francesa de Aillevillers-et-Lyaumont, ao pé da Alsácia-Lorena, portanto não muito longe da Suíça e da Alemanha, dizia sentir uma curiosidade inata pelas culturas diferentes da sua própria, justamente porque passara seus primeiros anos em uma faixa de fronteira, indagando-se como era a vida do outro lado. Era filho de um ferroviário e militante socialista, de quem herdou o espírito rebelde. Desde muito jovem, demonstrou interesse pelas sociedades africanas, como confessou nas primeiras páginas de seu livro Afrique ambiguë (1957).

Durante a ocupação da França pelos nazistas e a instauração do regime de Vichy, tornou-se um maquisard, ou seja, participou da resistência nos maquis (bosques). Terminada a guerra, acompanhou o esforço geral da nação imperial - e cheio de contradições e de idas e vindas - pela redefinição da política colonial francesa. Porém, decidiu defender algo muito além da propaganda aparentemente renovadora e ilusoriamente concessiva que havia sido oferecida às sociedades colonizadas pelo general De Gaulle e 
por alguns poucos administradores reformistas, a exemplo de Henri Laurentie. Em 1946, embarcou para o Senegal, e finalmente pôde conhecer de perto a realidade de um país africano. Em 1947, durante sua estadia na África Equatorial, escreveu seu primeiro livro, Tous comptes faits, curiosamente, uma obra de ficção, e sua única do gênero.

Já ao fim da década de 40, em Brazzaville, Balandier enviou o manuscrito de seu primeiro artigo científico para os Cahiers internationaux de sociologie, dedicado aos Fang do Gabão. Pouco depois, em Paris, visitou o fundador e editor da revista, o sociólogo russo Georges Gurvitch. Desde então, iniciaram uma intensa colaboração que durou quinze anos, até a morte deste último, em dezembro de 1965. Nesse período, Balandier publicou algumas de suas mais importantes monografias, como Sociologia atual da África Negra e Sociologia das Brazzavilles Negras (ambos de 1955), e o já mencionado África ambígua (1957). Depois desses, vieram mais cerca de vinte e cinco livros de sua autoria, o último deles publicado em 2013. O conjunto de sua obra trata dos temas os mais amplos possíveis - em prosseguimento aos princípios heurísticos do fenômeno social total, de Marcel Mauss, e dos patamares em profundidade, de Gurvitch -, desde estudos etnográficos até críticas da modernidade, do desenvolvimento, do subdesenvolvimento e da ardilosa noção de civilização. Certamente, uma das ideias mais esmiuçadas em seus escritos é a de "crise" e, para sua devida exposição - uma metáfora emprestada da óptica, para fins analíticos e eventualmente de intervenção política -, a noção de "revelador" (révélateur).

Mas seu texto de impacto mais duradouro para a antropologia e para a sociologia foi, sem dúvida, seu segundo artigo científico, publicado nos Cahiers em 1951,Notion desituation coloniale: approchetéorique. Nele, Balandier faz uma síntese dos pensamentos de Marcel Mauss, de Louis Wirth, de Max Gluckman, de Henri Wallon, de Octave Mannoni, de Jean-Paul Sartre, de Roger Bastide e do próprio Gurvitch, acerca CADERNOS CERU V. 27, n. 2, dez. 2016 dos conturbados processos de descolonização e de libertação nacional então em curso, ou já previstos para o continente africano. $O$ texto foi alterado e ampliado mais duas vezes, em consonância com as mudanças históricas em andamento, quando publicado como introdução das duas primeiras edições de Sociologia da África Negra (em 1955 e em 1963). No entanto, sua poderosa proposta de análise teórica permaneceu inalterada, e levou muitos etnólogos a reconsiderarem e a amplificarem seus reduzidos recortes espaciais no sentido de escalas mais amplas, as das "sociedades globais". Desse modo, lançou as bases do que depois descreveu como "método pouco respeitoso para com a fronteira erguida entre a etnologia e a sociologia" - novamente, aqui, a contingência da fronteira a ser suplantada.

Destarte, Balandier foi um dos principais expoentes do que um de seus célebres alunos, o suíço Jean Ziegler, depois identificou, com base em indicações do próprio Balandier, como o conjunto da escola "dinamista" (école dynamiste), ou ainda, da sociologia "generativa" (sociologie générative). Desse amplo movimento também fizeram parte Gurvitch e Roger Bastide (os pioneiros), Alfred Sauvy, o belga Henri Janne, Pierre George, o argelino Jacques Berque, Henri Desroche, Jean Cazeneuve, a brasileira Maria Isaura Pereira de Queiroz, o tunisiano Albert Memmi, o inglês Thomas Bottomore, Jean Duvignaud, Gilbert Durand, Edgar Morin, a búlgara Nora Mitrani, Paul Mercier, Louis Vincent Thomas, Claude Lefort, o belga Albert Doutreloux, Alain Touraine e a sul-africana Jacqueline RoumeguèreEberhardt, para citar apenas alguns dos nomes mais conhecidos.

À frente de instituições por ele fundadas, como o Centre d'études sur l'actuel et le quotidien, ou de associações legadas pelo velho Gurvitch, como os Cahiers internationaux de sociologie e a Association internationale des sociologues de langue française (AISLF), Balandier também formou um grande quadro de pesquisadores que depois se tornaram 
referências em suas áreas e temas de atuação, como os representantes da antropologia econômica Claude Meillassoux, Emmanuel Terray, Pierre-Philippe Rey, bem como Jean Copans. Também foram por ele orientados o mexicano Rodolfo Stavenhagen, a grega Marie Éliou, o japonês Junzo Kawada e a francesa Christine Messiant, uma grande especialista em política angolana. Também passaram por seus cursos, em Paris, os angolanos Mário Pinto de Andrade e Carlos Serrano e o congolês Kabengele Munanga. Muitos outros alunos africanos, entre os quais participantes de movimentos de libertação nacional, também acompanharam seus cursos. Seu principal interlocutor brasileiro, embora dez anos mais jovem, foi o sociólogo Fernando Mourão, que com ele sempre guardou grandes afinidades.

Até mesmo os militares portugueses que lideraram a chamada Revolução dos Cravos, em suas férias parisienses, quando de retorno das guerras de independência no Ultramar português, devem à leitura de seus livros uma tomada de consciência quanto à natureza desvelada de uma guerra racista $\mathrm{e}$ da "visão fascista do mundo", como lembrou depois um dos "capitães de Abril", o major Melo Antunes. Os autores do grupo politique par le bas, a saber, o camaronês Achille Mbembe, o togolês Comi Toulabor e o francês Jean-François Bayart, também devem muito a seu legado intelectual.

Alcunhado de "antropólogo das turbulências" (por Michel Maffesoli), ou, com justiça, de "um antropólogo de primeira linha" (por Jean Copans), recebeu inúmeras homenagens de seus antigos alunos e colegas da universidade. Pelo menos quatro coletâneas de textos são dedicadas a ele, e sua mais recente biografia intelectual foi publicada por Jean Copans em 2014. As poucas e infundadas críticas que lhe têm sido dirigidas não passam de mal-entendidos de maus leitores...

Balandier esteve pela primeira vez no Brasil nos anos 70. Ministrou aulas na Universidade de São
Paulo e na Universidade do Ceará, como recordou em seu livro de memórias Histoire d'Autres (1977). Em torno de uma dúzia de suas obras foram publicadas em língua portuguesa, no Brasil, em Portugal e em Angola. Recentemente, em dezembro de 2014, concordou em presentear os leitores brasileiros interessados em suas recordações e apontamentos, ao conceder uma longa entrevista, a ser publicada em 2017 no Brasil, pela revista de antropologia Mana, do Rio de Janeiro, e por uma publicação especial do Centro de Estudos Rurais e Urbanos (CERU), de São Paulo. Participaram da entrevista o professor François Germain Bonvin, da École des Hautes Études en Sciences Sociales (EHESS) e do CERU, também recentemente falecido, e os professores brasileiros Afrânio Garcia, da EHESS, e Cláudio Pinheiro, da Universidade Federal do Rio de Janeiro. Mais homenagens ainda estão por lhe ser prestadas, inclusive deste lado do Hemisfério.

21 de dezembro de 2016 